\title{
Executive Incentives and Innovation Performance-Based on the Information Technology Industry
}

\author{
Xu Liang, Xiaofeng Zhang, Yiyi Wang \\ School of Economics and Management, Beijing Jiaotong University, Beijing \\ School of Economics and Management, Beijing Jiaotong University, Beijing \\ School of Computer and Information Technology, Beijing Jiaotong University, Beijing \\ ijoan59@163.com, 1316377195@qq.com,wyy2843@163.com \\ Xu Liang
}

Keywords: Innovation performance, monetary incentives, equity incentives.

\begin{abstract}
In the rapid development of information technology, technological innovation has become an important driving force for enterprises to seek development and create advantages. For high-tech enterprises, it is of great significance to explore effective ways to achieve innovative performance, meet good development opportunities, and gain overall competitiveness. This paper uses the high-tech enterprises in 2008-2016 as a sample, examines the performance from the perspective of performance, and explores the impact of monetary incentives and equity incentives on the achievement of innovation performance. The results show that monetary incentives are positively correlated with corporate innovation performance significantly. Moreover, equity incentives are positively correlated with corporate innovation performance. In conclusion, both incentives are conducive to improving the innovation capability of enterprises and improving innovation performance. The research conclusion enriches the development of executive incentive theory, and provides a theoretical basis for the management of the company to adopt the incentive method scientifically and efficiently to promote the realization of innovation performance.
\end{abstract}

\section{Introduction}

The study of executive incentives is an important part of corporate governance and is being emphasized by scholars increasingly. Affected by economic development and policy orientation, innovation capability has gradually become the driving force for enterprise development. With the development of enterprises, the executive incentive system is constantly improving, and the owner prefers to use the monetary incentive and equity incentive methods to connect the interests of both parties, to promote the goal of both parties to be consistent, to solve the entrustment-agent problem existing in the enterprise, and to achieve the greatest corporate value. However, in the high-tech enterprises led by innovation, how the management uses the incentives scientifically to promote the realization of the innovation performance of the executives is still a management problem that needs to be solved urgently.

Based on the above background, this paper adopts the copywriting research method and numerical statistical analysis method, focusing on the high-tech industry, selecting the research perspective of the dynamic evolution mechanism, constructing the three-dimensional innovation index system, focusing on the influence of the executive incentives on the innovation process, so it can compensate for the lack of representativeness of the result of a single innovation variable.

This paper include two contributions. The first is to provide more detailed research materials for the development of executive motivation theory to improve the research in this field. The second is to formulate executive compensation and equity incentive system for enterprise science so that provides some inspiration to promote the realization of innovation performance. 


\section{Literature review}

\subsection{Proxy variables of innovation performance}

The choice of innovation performance indicators has always been one of the hot issues in academic research.

Domestic and foreign scholars have conducted in-depth research on this, and the innovation performance indicators have evolved from the selection of individual agent variables to the formation of innovative performance evaluation systems. Some scholars use a single agent variable to evaluate innovation performance. For example, Xu Yu and Feng Junke(2017) ${ }^{[1]}$ use "the number of patents filed during the year" as a measure of innovation performance. Sun Wei and Gao Yameng (2017) ${ }^{[2]}$ use enterprise $R \& D$ investment as a proxy variable to conduct related research.

However, with the changes in the development of innovation, it is clear that a single evaluation indicator can not fully reflect the value of the innovation process. Beginning with the dynamic competence theory framework proposed by Teece and Pisano (1994) ${ }^{[3]}$, scholars have gradually developed their researches on the performance evaluation system of innovation. Xu Ning, Xu Peng, and Wu Chuang (2014) ${ }^{[4]}$ propose a dynamic integration model of technological innovation to make up for the shortcomings of measuring innovation performance in a single dimension, and the performance evaluation system of innovation began to mature. Therefore, based on the dynamic capability theory, this paper selects the dynamic integration model of technological innovation as a measure of innovation performance.

\subsection{Researches on the relationship between different incentives and innovation performance}

With the proposal and development of the principal-agent theory, the agency problem between corporate shareholders and executives has received more and more attention. Many scholars have devoted themselves to the relationship between executive incentives and innovation input, and confirmed that effective incentives can inhibit the risk aversion behavior of executives. At the same time, there are also opposite views.

Prior to this, most of the company's senior executives were in the stage of wealth accumulation, so proper monetary incentives can promote the investment of senior executives. However, with the development of the enterprise, the separation of the two rights becomes more and more obvious. In order to repair the agency problem, the owner tends to give the executive a certain residual claim, so that it can be operated as a part of the company. Therefore, the equity incentive is also recognized and used by the owners.

In terms of monetary incentives, scholars at home and abroad generally believe that monetary incentives can effectively suppress the contradiction of principal-agents and mobilize the enthusiasm of enterprise executives. For example, researches of Romero-Merino (2012) ${ }^{[5]}$ show that as the level of managerial compensation increases, the number of $R \& D$ patents and related expenditures of enterprises change in the same direction. Domestic scholars such as Yin Meiqun, Sheng Lei, and Li Wenbo (2018) ${ }^{[6]}$ also find that monetary incentives could positively regulate the role of innovation input in promoting corporate performance. There are also some scholars get different research conclusions. Jiang Tao and Wang Huaiming (2017) ${ }^{[7]}$ use Chinese state-owned enterprises as the research object and find that the shape of innovation performance and executive compensation is Ushaped.

In terms of equity incentives, scholars have also concluded different conclusions about their relationship. Foreign scholars such as Dong and Gou $(2010){ }^{[8]}$ conduct multiple regression tests on 142 Chinese companies' data and find that there is a significant positive correlation between executive equity incentives and innovation performance. Sun Hui and Yang Wangwei(2019) ${ }^{[9]}$ study 1022 Ashare listings from 2014 to 2016, and find that two ways of equity incentives have a negative effect on the impact of innovation performance.

It can be seen that the conclusions from the existing literature are not the same. The first reason is the difference of sample types lead to the slightly different conclusions of the targeted research for a certain stage. Secondly, the choice of the agent parameters of the innovation performance is multiple. One is from the perspective of innovation investment, which uses R\&D investment as an indicator of 
innovation performance evaluation. The other is from the perspective of innovation output, which uses the number of patents as performance evaluation indicators of innovation. However, both methods fail to consider the complexity of the innovation process and the variability of the business environment, hence, the in-depth development of research has been limited.

\section{Research design}

\subsection{Research hypothesis}

Previous studies have based on different incentives, different industry sample, and different innovation performance agent variables. On one hand, the incentive method includes many forms, which forms a divergence of research conclusions. On the other hand, the choice of proxy variables for innovation performance cannot reflect the entire innovation process, and needs to be compensated based on the proxy variables of the innovation dynamic integration model.

Based on the above theoretical analysis, this paper proposes the following assumptions:

H1: Executive monetary incentives are positively related to innovation performance;

$\mathrm{H} 2$ : Executive equity incentives are positively related to innovation performance;

\subsection{Variable definition}

\subsubsection{Sample data selection}

This paper selects the data of high-tech industries in the A-share listed companies from 2008 to 2016, and eliminates the data of incomplete data and ST company data, and finally obtains 400 valid research samples. The data is mainly from the CSMAR database, using Stata14.0 and SPSS19.0 statistical software for metrological analysis.

\subsubsection{Executive incentives}

The incentives for executives include monetary incentives, equity incentives, promotion incentives, etc. In this paper, equity incentives and monetary incentives are defined only, choose the universal definition, which is the logarithm of the top three executive compensation to indicate the degree of monetary incentives (LnPay). According to Xu Ning's (2013) [10] approach, the top three executives' shareholdings is chosen to measure equity incentives (MSR).

\subsubsection{Innovation performance}

According to $\mathrm{Xu}$ Ning's definition method, select R\&D expenditure as a percentage of operating income (R\&D), total number of annual invention applications (NOI), annual patent applications (NOP), intangible assets increments (IA), etc., which can represent innovative performance indicators to build innovative performance TIDC indicator. It can avoid measuring from a single dimension, and make the analysis results more scientific.

First, make factor analysis of these indicators. The KMO value is 0.50 . In the Bartlett spherical test, the significant level Sig. is less than 0.1. In summary, this sample can be used for factor analysis.

Table 1 factors explain the total variance of the original variables

\begin{tabular}{cccccccccc}
\hline \multicolumn{2}{c}{ Component } & \multicolumn{2}{c}{ initial eigenvalue } & \multicolumn{2}{c}{ extraction load square sum } & \multicolumn{3}{c}{ rotation load square sum } \\
Total & $\begin{array}{c}\text { variance } \\
\text { percentage }\end{array}$ & $\begin{array}{c}\text { cumulative } \\
\text { \% }\end{array}$ & total & $\begin{array}{c}\text { variance } \\
\text { percentage }\end{array}$ & $\begin{array}{c}\text { cumulative } \\
\%\end{array}$ & total & $\begin{array}{c}\text { variance } \\
\text { percentage }\end{array}$ & $\begin{array}{c}\text { cumulative } \\
\%\end{array}$ \\
\hline 1 & 1.171 & 29.264 & 29.264 & 1.171 & 29.264 & 29.264 & 1.092 & 27.3 & 27.3 \\
2 & 1.017 & 25.435 & 54.699 & 1.017 & 25.435 & 54.699 & 1.088 & 27.19 & 54.49 \\
3 & 1.002 & 25.058 & 79.757 & 1.002 & 25.058 & 79.757 & 1.011 & 25.267 & 79.757 \\
4 & 0.81 & 20.243 & 100 & & & & & & \\
\hline
\end{tabular}

Three main factors are extracted from the four indicators, which can replace the information contained in the original index. The result of SPSS processing shows the cumulative variance contribution rate of the main factors reached $79.757 \%$. 
It is observed that the first factor F1 has a high load on the invention quantity and R\&D expenditure, the second factor F2 has a high load on the number of patents, the third factor F3 has a high load on intangible assets.

Table 2 Factor score coefficient matrix

\begin{tabular}{cccc}
\hline & \multicolumn{3}{c}{ Components } \\
& 1 & 2 & 3 \\
\hline R\&D & -0.469 & -0.453 & -0.159 \\
NOI & 0.821 & -0.173 & -0.09 \\
NOP & -0.161 & 0.829 & -0.088 \\
IA & -0.034 & -0.039 & 0.974 \\
\hline
\end{tabular}

According to the factor score coefficient, the score formulas of F1 and F2 can be obtained:

$$
\begin{gathered}
\mathrm{F} 1=-0.469 * \mathrm{R} \& \mathrm{D}+0.821 * \mathrm{NOI}-0.161 * \mathrm{NOP}-0.034 * \mathrm{IA} \\
\mathrm{F} 2=-0.453 * \mathrm{R} \& \mathrm{D}-0.173 * \mathrm{NOI}+0.829 * \mathrm{NOP}-0.039 * \mathrm{IA} \\
\mathrm{F} 3=-0.159 * \mathrm{R} \& \mathrm{D}-0.09 * \mathrm{NOI}-0.088 * \mathrm{NOP}+0.974 * \mathrm{IA}
\end{gathered}
$$

Taking the variance contribution rate of two factors as the weight, the formula for calculating the final score is:

$$
\mathrm{TIDC}=27.3 \% * \mathrm{~F} 1+27.19 \% * \mathrm{~F} 2+25.267 \% * \mathrm{~F} 3
$$

\subsubsection{Control variables}

In order to ensure the stability of the study, four control variables are selected:

Company size (Size): the natural number of the company's total assets.

The shareholding ratio of the largest shareholder (Top): the proportion of the total shareholding of the largest shareholder at the end of the year.

Debt ratio (Level): the ratio of corporate liabilities to total assets.

\begin{tabular}{|c|c|c|}
\hline The nature of the variable & Name & Symbol \&Calculation method \\
\hline Interpreted variables & $\begin{array}{l}\text { innovation performance } \\
\text { (TIDC) }\end{array}$ & TIDC factor analysis \\
\hline Explanatory variables & $\begin{array}{l}\text { Executive monetary } \\
\text { incentives (LnPay) }\end{array}$ & logarithms of L nPay's top three executives' salaries \\
\hline Interpretation variables & $\begin{array}{l}\text { Executive equity } \\
\text { incentives (MSR) }\end{array}$ & MSR top three executives share \\
\hline Control variable & company size (Size) & logarithm of Size company total asset \\
\hline Control variable & $\begin{array}{c}\text { The shareholding ratio of } \\
\text { the first largest } \\
\text { shareholder (Top) }\end{array}$ & Top year's largest shareholder holdings \\
\hline Control variable & debt ratio (Level) & Level liability as a percentage of total assets \\
\hline Control variable & $\begin{array}{l}\text { Two-time part-time } \\
\text { situation (Par) }\end{array}$ & Par if the same person uses " 1 ", and vice versa "0" \\
\hline
\end{tabular}

The two roles of the chairperson and the general manager (Par): If it is the same person, "1" represents it; if it is not the same person, " 0 " represents it.

Table 3 Variable definition 
4. Empirical test analysis

\subsection{Sample descriptive statistics}

Table 4 Descriptive analysis

\begin{tabular}{cccccc}
\hline Variables & $\begin{array}{c}\text { observation } \\
\text { value }\end{array}$ & mean value & $\begin{array}{c}\text { standard } \\
\text { deviation }\end{array}$ & minimum value & maximum value \\
\hline TIDC & 280 & -0.008 & 0.458 & -3.64 & 1.79 \\
LnPay & 280 & 13.997 & 0.882 & 11.002 & 16.405 \\
MSR & 280 & 0.032 & 0.066 & 0 & 0.365 \\
Size & 280 & 21.026 & 0.993 & 18.229 & 23.077 \\
Top & 280 & 27.023 & 12.945 & 6.48 & 64.62 \\
Level & 280 & 0.423 & 0.242 & 0.019 & 1.594 \\
Par & 280 & 1.893 & 0.31 & 1 & 2 \\
\hline
\end{tabular}

It can be seen from the table that the average value of TIDC is -0.008 , indicating that the industry's ability to achieve innovation performance is relatively insufficient. At the level of executive incentives, for monetary incentives, the average value of the total remuneration of board of directors and supervisors is 13.997, but the distribution is much scattered. As for equity incentives, quite a few companies do not use this method. We analyze the remaining control variables and the results indicate that the samples can be used for analysis.

\subsection{Correlation analysis}

Table 5 Relevant analysis

\begin{tabular}{cccccccc}
\hline & TIDC & LnPay & MSR & Size & Top & Level & Par \\
\hline TIDC & 1 & & & & & & \\
LnPay & $0.266^{* * *}$ & 1 & & & & & \\
MSR & 0.010 & -0.039 & 1 & & & & \\
Size & $0.348^{* * *}$ & $0.51^{* * *}$ & -0.063 & 1 & & & \\
Top & 0.05 & -0.02 & $-0.236^{* * *}$ & 0.038 & 1 & & \\
Level & 0.025 & $-0.248^{* * *}$ & $0.137^{* *}$ & $-0.349^{* * *}$ & 0.043 & 1 & \\
Par & 0.025 & 0.024 & -0.097 & 0.01 & 0.036 & $-0.191^{* * *}$ & 1 \\
\hline
\end{tabular}

$* * *, * *, *$ represent the level of significance at $1 \%, 5 \%$, and $10 \%$ respectively.

From Table 5, the correlation coefficient between the enterprise's monetary incentive (LnPay) and innovation performance (TIDC) is significantly positive at $1 \%$ significant level. The correlation coefficient between equity incentives (MSR) and TIDC is positive. However, it is not outstanding, so it may be necessary to refine the equity incentives for more in-depth research.

\subsection{Regression analysis}

We establish the following models for hypotheses 1,2 :

$$
\begin{gathered}
\operatorname{Tidc}_{\mathrm{i}, \mathrm{t}}=\beta_{0}+\beta_{1} \operatorname{Lnpay}_{i, t}+\beta_{2} \sum X_{i, t}+\varepsilon_{i, t}+u_{i} \\
\operatorname{Tidc}_{\mathrm{i}, \mathrm{t}}=\beta_{0}+\beta_{1} M S R_{i, t}+\beta_{2} \sum X_{i, t}+\varepsilon_{i, t}+u_{i}
\end{gathered}
$$

In the two models of hypotheses, $\beta_{0}$ represents the intercept, $\beta_{i}$ represents the regression coefficient, $X_{i}$ represents a set of control variables, and $T_{i d c}{ }_{i}$ represents the innovation performance of the enterprises. 
Table 6 Regression Analysis of Executive Incentives and Firm Performance

\begin{tabular}{ccc}
\hline Variables & Monetary incentive & Equity incentive \\
\hline LNPAY & $0.072^{* *}$ & - \\
MSR & $(0.034)$ & 0.022 \\
SIZE & - & $(0.401)$ \\
& $0.157^{* * *}$ & $0.188^{* * *}$ \\
TOP & $(0.031)$ & $(0.028)$ \\
& 0.001 & 0.001 \\
Level & $(0.002)$ & $(0.002)$ \\
& $0.355^{* * *}$ & $0.334^{* * *}$ \\
Par & $(0.115)$ & $(0.116)$ \\
& 0.079 & 0.080 \\
C & $(0.084)$ & $(0.084)$ \\
& $-4.646^{* * *}$ & $-4.283^{* * *}$ \\
Adj-R & $(0.648)$ & $(0.631)$ \\
F statistic & 0.148 & 0.133 \\
p value & 10.65 & 9.59 \\
F statistic & 0.000 & 0.000 \\
p value & &
\end{tabular}

$* * *, * *, *$ represent the level of significance at $1 \%, 5 \%$, and $10 \%$ respectively.

Table 6 shows the regression analysis results of executive monetary incentives and equity incentives are both positive, which indicates that the implementation of monetary incentives and equity incentives can promote the development of innovation and the rapid realization of innovation performance. Assume that 1, 2 is established.

\subsection{Robustness test}

There are many methods for robustness testing. Considering the possibility of indigeneity problems, GMM estimation methods are used to reduce the interference of endogenous problems.

Table 7 GMM Estimation Coefficient Table for Executive Incentives for Firm Performance

\begin{tabular}{ccc}
\hline Variables & Currency incentive & Equity incentive \\
\hline TIDC(-1) & $0.122 * * *$ & $0.130 * *$ \\
LNPAY & $(0.008)$ & $(0.056)$ \\
& $0.079 * * *$ & - \\
MSR & $(0.018)$ & 0.722 \\
& - & $(1.065)$ \\
cons & - & $-3.424 * *$ \\
& $-3.532 * * *$ & $(1.509)$ \\
AR(1) & $(0.267)$ & 0.009 \\
AR(2) & 0.008 & 0.452 \\
Sargan & 0.326 & 0.857 \\
\hline
\end{tabular}

$* * *, * *, *$ represent the level of significance at $1 \%, 5 \%$, and $10 \%$ respectively 
From Table 7, it can be seen that the lagging one-phase coefficient of enterprise performance is significantly positive, which represents that the performance of the previous period has a positive impact on the current period. The regression coefficients of executive monetary incentive and equity incentive to innovation performance are both positive at $5 \%$ significant level.

\section{Research conclusions}

From the empirical results, it can be seen that both the monetary incentives and the equity incentives of the executives are significantly positively correlated with the innovation performance of the enterprises. However, comparing the two methods, we find that there are few enterprises in the sample enterprises with equity incentives as the main incentive method. The management does not prefer to use equity incentives to achieve performance. From the research results, it can be found that the equity incentives are less significant than the currency incentives. It shows that the application of equity incentives in high-tech enterprises is really little, and the incentive effect is not obvious. It is necessary to improve the efficiency and quality of incentives furtherly.

To a certain extent, this paper enriches the research data of executive incentive theory, especially equity incentive theory. However, the application of equity incentives in the industry is not extensive and the research on equity incentives from the perspective of integration is not targeted. The effect of the reflection is not clear. In the era of new economic changes, the importance of equity incentives should be gradually valued and selected by the managers. Among them, in the aspect of improving the quality of executives' equity incentives, we can conduct a comparative study on incentives such as incentive equity incentives and welfare equity incentives. The best way to motivate is to bring more deterministic income. In addition, because high-tech enterprises have certain listing thresholds, there is still a large proportion of non-listed innovative companies. The future research can try to overcome the problem of information collection and explore the "innovation incentives and innovations of non-listed innovative companies" to fills the gaps in research.

\section{References}

[1] $\mathrm{Xu} \mathrm{Yu,} \mathrm{Feng} \mathrm{Junke.} \mathrm{Internal} \mathrm{Control,} \mathrm{Executive} \mathrm{Incentives} \mathrm{and} \mathrm{Innovation} \mathrm{Performance-An}$ Empirical Study Based on the Effectiveness of Internal Control [J]. Soft Science, 2017,31(2):7982. DOI:10.13956/j. ss.1001-8409.2017.02.17.

[2] Sun Wei; Gao Yameng. Research on the Relationship between Innovation Performance and Executive Compensation of China's Growth Enterprise Market Listed Companies [J]. Science \& Technology and Industry, 2017, 17(12): 122.

[3] Teece, D.; Pisano, G. The dynamic capabilities of firms: an introduction. Industrial and Corporate Change, v.1, n.3, 1994.

[4] $\mathrm{Xu}$ Ning, $\mathrm{Xu}$ Peng, $\mathrm{Wu}$ Chuang. The Construction of Technological Innovation Dynamic Capabilities and Its Value Creation Effect___Verified from Small and Medium-sized Listed Companies [J]. Science of Science and Technology Management,2014(8)

[5] GARC í A-MANJóN J V, ROMERO-MERINO M E. Research, development, and firm growth. Empirical evidence from European top R\&D spending finns [J]. Research Policy, 2012, 41 (6): 1084-1092.

[6] Yin Meiqun, Sheng Lei, Li Wenbo. Executive Incentives, Innovation Input and Corporate Performance_an Empirical Study Based on Endogenous Perspective [J]. Nankai Management Review, 2018, 21(01): 109-117.

[7] Jiang Tao, Wang Huaiming. The Impact of Executive Incentives on R\&D Investment in High-tech Enterprises_-Based on the Perspective of Actual Controller Types [J]. Research and Development Management, 2012, 24(4): 53-60. DOI:10.3969 /j.issn.1004-8308.2012.04.007 
[8] Jing D and Gou Y-N. Corporate governance structure, manage discretion and R\&D investment in China [J]. International Review of Economics \& Finance, 2010 19(2): 180-188

[9] Sun Hui, Yang Wangwei. Executive Incentives, Innovation Input and Innovation Performance-Based on the Regulating Effect of Executive "Double Dollar" Capital [J].Science and Technology Management Research, 2019,39(10):9-16. :10.3969/j. issn.1000-7695.2019.10.002.

[10] Xu Ning. The Promotion Effect of Equity Incentives of High-tech Companies on R\&D Investment_-An Empirical Study of Nonlinear Perspectives [J]. Science of Science and Technology Management, 2013,34(2):12-19

[11] Zhai Shengbao, Chen Ziwei. Equity Incentives and Enterprise Innovation of Executives [J]. Journal of Beijing Technology and Business University (Social Science Edition), 2016, 31(1): 8593. DOI:10.16299/j.1009-6116.2016. 01.010.

[12] Yu Xueran Hu Yan. Executive Incentives and Innovation Input__Experience Data from GEM [J]. Journal of Capital University of Economics and Business, 2015,17(1).

[13] Zhou Ting. An Empirical Study on the Relationship between Executive Compensation and Corporate Performance [J]. Contemporary Agricultural Machinery, 2019, (7): 74-76. DOI: 10.3969/J.ISSN.1673-632X.2019.07.007.

[14] Lu Xin, Li Ruihong, Fang Ruiqi. Research on the relationship between executive promotion incentives and innovation investment of state-owned enterprises [J]. Economics and Management, 2019, 33 (03): 86-92.

[15] Li Ling, Chen Xi, Zhang Wei. Earnings Volatility, Executive Incentives and Enterprise R\&D Investment_based on the Empirical Data of GEM Listed Companies [J].Friends of Accounting, 2019(01):117-121. 